\title{
Tecnologias computacionais na formação continuada de professores durante a pandemia
}

computational technologies in continuing teacher ealucation during the pandemic

Flábia Alves Lopes* Maria do carmo barbosa de melo** 


\section{RESUMO}

Circunscrito às preocupações dos poderes públicos acerca das condições dos professores, especialmente em realidade tão atípica como a atual, o presente artigo se propõe a contribuir com discussão e formação em torno das tecnologias digitais para professores da rede pública, considerando aspectos metodológicos e ferramentais. Pensando no desafio que a pandemia de covid-I9 evidenciou como a irrefutável desigualdade social e a imensa pressão canalizada para os professores, serão analisadas as possíveis interações entre as tecnologias, a problemática da formação continuada dos professores em contexto emergencial e o panorama da educação pública durante e após o isolamento social. As tecnologias e as propostas de formação docente continuada apresentadas neste artigo foram formuladas com base em revisões de literatura sobre temas pertinentes ao contexto e em análises documentais de algumas tecnologias disponíveis e adequadas à finalidade da pesquisa.

Palavras-chave: Tecnologias digitais na educação. Formação continuada de professores. Pandemia.

\section{ABSTRACT}

Considering the concerns of public authorities about the conditions of teachers, especially in a reality as unusual as the current one, this article discusses tools and methodologies that can be used to ensure the continuing education of teachers in the Brazilian public system during the pandemic. For this, we performed a literature review and a documentary analysis of some of the available technologies. We also reflected on the possible interactions between technologies, the problem of continuing teacher education in an emergency context and the panorama of public education during and after social isolation.

Keywords: Digital technologies in education. Continuing teacher education. Pandemic. 


\section{INTRODUÇ̃̃o}

Desde a popularização das tecnologias, passamos a experimentar uma diferente relação com o mundo. Mudamos vocabulário, forma de nos relacionar, de pensar, de agir, "cancelamos" pessoas e até criamos "bolhas" com direcionamentos políticos, culturais, sociais, éticos, ou seja, criamos novos hábitos. Essas transformações digitais diárias, que impactam nosso cotidiano de diferentes formas, avultaram-se quando, de forma inesperada e ainda não vivida pela maioria da população mundial contemporânea, passamos a conviver com uma pandemia de grandes proporções causada pelo vírus Sars-CoV-2 (severe acute respiratory syndrome coronavirus 2). Uma doença causada por uma espécie de coronavírus e conhecida como covid-I9, que desencadeia uma síndrome respiratória aguda grave com contágio silencioso, sintomático ou assintomático, entre seres humanos, e que, em muitos casos, é letal.

A princípio tínhamos a impressão de que seria algo passageiro e que, com 20 ou 30 dias, voltaria tudo ao normal, mas os dados de contágios e óbitos nos mostraram o quanto estávamos enganados. A partir da segunda quinzena do mês de março de 2020 , mudanças significativas começaram a acontecer. Iniciou-se uma reorganização de tudo que conhecíamos. Comércio fechado, apenas serviços essenciais continuaram funcionando, medidas urgentes de distanciamento foram tomadas, aeroportos e praias fechadas, festas canceladas e proibidas as aglomerações, ou seja, impacto na vida de todos, independentemente da profissão, status social ou país.

Os efeitos da pandemia também foram sentidos de modo consideravelmente invasivo no domínio escolar. A presença do vírus determinou o fechamento generalizado de escolas e universidades em todo o planeta. Assim como todos os países, o Brasil seguiu as orientações da OMS e as instituições de ensino presencial foram fechadas. O Censo Escolar de 2019 constatou que havia na educação básica (educação infantil, ensino fundamental e médio) 47,9 milhões de alunos matriculados no país, tanto em escolas públicas quanto em particulares, sem contar as universidades e as demais instituições de ensino superior. Desde o início da epidemia, todos esses estudantes foram confinados em suas casas, a princípio sem aula.

Com esse cenário de incertezas, e motivados pela necessidade de reduzir a disseminação do vírus, os governos estaduais passaram a investir em estratégias emergenciais para oferecimento das aulas durante o isolamento social. Dessa forma, a educação adquiriu uma "nova modalidade" em sua rotina, o ensino remoto.

Com base nesse contexto, o presente artigo pretende discutir possibilidades da formação docente continuada que se ajustem às novas habilitações nas diversas modalidades tecnológicas, exigidas no ensino remoto e também presencial.

\section{RETRATO DO PROFESSOR NO BRASIL EM TEMPOS DE COVID-19}

Diante dessa nova realidade, o Ministério da Educação (MEC) emitiu a portaria $\mathrm{n}^{\circ} 343$, de $\mathrm{I} 7$ de março de 2020 , que autorizou instituições de ensino a substituir 
A pandemia e suas

derivações descortinaram

o quanto todo o sistema

educacional brasileiro

estava despreparado e

sem infraestrutura para

proporcionar acesso

à rede mundial de

informação

suas aulas presenciais por meios digitais enquanto durar a pandemia de covid-I9'. Diante dessa nova situação, criou-se o impasse para o professor: "Como não ter e ter que ter pra dar?"

Como consequência, os professores brasileiros tiveram de se adaptar a essa modalidade de ensino sem formação específica para a interação com as ferramentas necessárias para a prática da docência em ambientes virtuais. E, como agravante da situação, convivendo com dificuldades estruturais e sendo obrigados a se adaptar aos novos contextos em um curto espaço de tempo, sem o necessário apoio financeiro, técnico e psicológico.

A questão da infraestrutura de tecnologia educacional já era problemática antes da incidência da covid-I9. Essa situação foi denunciada em um relatório do Banco Mundial $^{2}$ emitido em 20I7, que apontava a falta de infraestrutura preexistente e a necessidade de políticas públicas que visassem à formação tecnológica dos professores. Tais providências não foram tomadas em momento oportuno, embora o Plano Nacional de Educação (PNE) indicasse a incorporação das modernas tecnologias de informação e comunicação, em consonância com a Base Nacional Comum Curricular, da educação básica. O resultado é que os problemas relacionados à pandemia expuseram o descaso governamental relativo à introdução de temas de tecnologia na

1 "O ministro de Estado da Educação, no uso da atribuição que lhe confere o art. 87, parágrafo único, incisos I e II, da Constituição, e considerando o art. $9^{\circ}$, incisos II e VII, da lei n 9.394, de 20 de dezembro de 1996, e o art. $2^{\circ}$ do decreto $n^{\circ} 9.235$, de 15 de dezembro de 2017, resolve:

Art. $1^{\circ}$ : autorizar, em caráter excepcional, a substituição das disciplinas presenciais, em andamento, por aulas que utilizem meios e tecnologias de informação e comunicação, nos limites estabelecidos pela legislação em vigor, por instituição de educação superior integrante do sistema federal de ensino, de que trata o art. $2^{\circ}$ do Decreto $n^{\circ} 9.235$, de 15 de dezembro de 2017.

$\S 1^{\circ} \mathrm{O}$ período de autorização de que trata o caput será de até trinta dias, prorrogáveis, a depender de orientação do Ministério da Saúde e dos órgãos de saúde estaduais, municipais e distrital." (BRASIL, 2020)

2 "A política depende de infraestrutura preexistente e almeja oferecer aos professores o treinamento adequado e combinar tecnologias para incluir o maior número possível de alunos. Nessas circunstâncias, o efetivo aprendizado remoto e o treinamento de professores no uso pedagógico da tecnologia são políticas complementares." (BANCO MUNDIAL, 2020, p. 21) 
formação dos professores e no ambiente escolar, resultando na atual crise da educação, principalmente nas escolas públicas.

A pandemia e suas derivações descortinaram o quanto todo o sistema educacional brasileiro estava despreparado e sem infraestrutura para proporcionar acesso à rede mundial de informação. É possível que o impacto causado pelo coronavírus tenha efeito perenal sobre a educação no país, e a escola pós-pandemia será desafiada não só pela sanitarização da instituição, mas também pelo choque econômico familiar que deverá afetar o retorno à escola. Os abismos sociais tenderão a aumentar. Mesmo que a escola venha revendo suas estratégias, processos, estruturas e metodologias, há urgência por um trabalho em grupo alinhado, entre professores, gestores, técnicos administrativos e secretarias de educação.

A atuação do professor tem passado por fortes mudanças nesse contexto, geralmente pela adição de novas funções. No tempo presente, além da produção e transmissão de conhecimento, o docente está acumulando as funções de moderador de sala de aula virtual e formatador de conteúdos a distância. Tudo de forma acumulada e emergencial. Sua residência, antes espaço privado, passou a espaço público de realização e transmissão de aulas remotas. Neste contexto de enormes mudanças se faz premente a instituição de modelos sólidos e acessíveis de formação docente continuada, repensada e rearticulada para o contexto educacional vigente, e que inclua as competências e habilidades necessárias para pleno uso das tecnologias digitais da informação e comunicação (TDICs).

Competência representa o resultado do diálogo entre habilidades e aptidões que possuímos, as quais acionamos para buscar um novo patamar de equilíbrio quando entramos em desequilíbrio, pois há uma transformação a ser processada (ALLESSANDRINI, 2002, p. I64-I65).

As gerações recentes, que nasceram e cresceram no decorrer da disseminação dos meios tecnológicos, denominadas por Prensky (200I) nativos digitais, embora frequentem salas de aula como seus pais, antes da covid-19, são bem diferentes deles. Cresceram acostumadas com a rapidez do hipertexto, o crescente fluxo de informações, o acesso a mídias de qualquer parte do planeta, as redes sociais diversas, as bibliotecas, museus, filmes, mensagens, pesquisas e o mundo em seu bolso por intermédio do celular. Elas estão conectadas em cada momento de suas vidas, o que lhes confere uma percepção peculiar acerca do mundo. Essas circunstâncias também afetam os aspectos cognitivos dos sujeitos, que acabam por assimilar novos modos de aprender, frequentemente desafiadores para os professores. Prensky (200I) observa que

agora fica claro que como resultado deste ambiente onipresente e o grande volume de interação com a tecnologia, os alunos de hoje pensam e processam as informações bem diferentemente das gerações anteriores. Essas diferenças vão mais longe e mais intensamente do que muitos educadores suspeitam ou percebem. E "tipos distintos de experiências levam às distintas 
estruturas de pensamento", diz o dr. Bruce D. Barry, da Faculdade de Medicina Baylor (p. I).

Diante dessas distintas perspectivas geracionais, que tipo de investimento deveria ter sido feito na formação dos professores, tanto em sua etapa inicial como na continuada? A nosso ver, as consequências da pandemia respondem rapidamente a essa questão.

\section{APRENDIZAGEM EXPERIENCIAL}

Por estarem imersos nas TDICs, os nativos digitais aprendem de acordo com seus interesses e experiências. Esse modelo de aprendizagem é denominado modelo experiencial. Como diz Kolb (1984), "o processo pelo qual o conhecimento é criado acontece por meio da transformação da experiência. O conhecimento resulta da combinação de se obter e transformar a experiência."

A teoria da aprendizagem experiencial foi desenvolvida por David Kolb com base nas teorias conceituais de Jean Piaget, John Dewey e Kurt Lewin (AKELLA, 20Io), e propõe que o conhecimento é adquirido por meio da experiência e que "aprender fazendo" é uma das formas mais eficazes na obtenção de conhecimentos.

A aprendizagem experiencial tende a reforçar a interdependência entre os atributos particulares de quem está aprendendo e o que ocorre ao seu redor, seja o conhecimento originado de experiências pessoais ou sociais. A aprendizagem é individual. Em compensação, vida social e educacional se retroalimentam e se prolongam. Toda educação é social. Nesse sentido, faz-se necessário mobilizar saberes considerando que a realidade é multidimensional; assim, não se pode deixar de renovar o pensamento, ponderando as rígidas fronteiras acadêmicas e priorizando resultados satisfatórios de aprendizagem, como bem alerta Kolb (1984):

$\mathrm{O}$ processo de aprendizagem advindo da experiência determina e atualiza o desenvolvimento potencial. Essa aprendizagem é um processo social; portanto, o curso de desenvolvimento individual é determinado pelo sistema cultural e social de conhecimento (p. I33).

\section{E Elkjaer (2000) complementa quando explicita que}

a experiência não deriva da mera atividade, mero fazer, e não está baseada em qualquer mudança que implique reflexão sobre ações anteriores com o fim de antecipar consequências futuras. A simples participação na prática, na ação, não cria aprendizagem. Uma pessoa está aprendendo somente quando é capaz de refletir sobre suas ações e reorganizar, assim como reconstruir a experiência, por meio de um processo contínuo de reflexão - pensamento - como meio de atuação. A ideia de aprendizagem como reorganização e reconstrução da experiência não é uma questão de argumentar a favor ou contra a cognição (p. II3). 
Diante dessas relevantes considerações, especialmente a de que a experiência é a base para o desenvolvimento, entende-se ser necessário e premente que o processo de ensino-aprendizado não sofra descontinuidade ao longo de toda a vida do indivíduo, inclusive na sua trajetória escolar. Por isso, a escola precisará rever suas estratégias metodológicas e torná-las mais ativas e inovadoras.

\section{ACESSO À INTERNET NA EDUCACÃO COMO DIREITO HUMANO FUNDAMENTAL}

No ano de 2019 o instituto de pesquisa YouGov³, em associação com a Google for Education, numa pesquisa inédita no país, intitulada Challenger ${ }^{4}$, entrevistou por meio de formulários on-line 300 educadores e 500 responsáveis por alunos no país. A pesquisa obteve os seguintes resultados:

\begin{tabular}{|l|l|}
\hline \multicolumn{1}{|c|}{ Professores* } & \multicolumn{1}{c|}{ Pais } \\
\hline $\begin{array}{l}\text { 95\% acreditam que trazer a tecnologia para } \\
\text { a sala de aula prepara os estudantes para o } \\
\text { futuro; }\end{array}$ & $\begin{array}{l}\text { 91\% acreditam que a tecnologia na sala de } \\
\text { aula torna o aprendizado mais envolvente; }\end{array}$ \\
\hline $\begin{array}{l}\text { 82\% estão preocupados com a equidade } \\
\text { de acesso quando se trata de tecnologia } \\
\text { nas escolas; }\end{array}$ & $\begin{array}{l}\text { 88\% acreditam que a tecnologia ajuda os } \\
\text { estudantes a reter informação; }\end{array}$ \\
\hline $\begin{array}{l}\text { 77\% aponta que o maior desafio é envolver } \\
\text { os alunos; }\end{array}$ & $\begin{array}{l}74 \% \text { concordam que a tecnologia permite } \\
\text { que alunos aprendam em seu próprio ritmo; }\end{array}$ \\
\hline $\begin{array}{l}\text { 95\% concordam que trazer a tecnologia } \\
\text { para a sala de aula pode tornar o aprendi- } \\
\text { zado mais atraente para os alunos; }\end{array}$ & $\begin{array}{l}\text { 47\% acham que a tecnologia é atualmente } \\
\text { aprendizagem dos alunos. }\end{array}$ \\
\hline $\begin{array}{l}\text { 60\% dizem que não têm tempo suficiente } \\
\text { para fazer tudo que é necessário; }\end{array}$ & \\
\hline $\begin{array}{l}\text { 90\% concordam que a tecnologia pode } \\
\text { ajudá-los a economizar tempo; }\end{array}$ & \\
\hline $\begin{array}{l}\text { 81\% acreditam que a parte mais importan- } \\
\text { te do seu trabalho é ensinar aos alunos as } \\
\text { habilidades do futuro. }\end{array}$ & \\
\hline
\end{tabular}

Fonte: YouGov e Google Discovery.

* Pesquisa realizada pelo YouGov e Google Discovery

Mesmo com uma amostra não muito grande, se considerarmos o tamanho do Brasil, a pesquisa tornou-se um importante panorama do país pelo seu alcance, já que foi aplicada nas cinco regiões do país, com responsáveis e docentes da educação fundamental e ensino médio em escolas públicas, privadas e instituições sem fins lucrativos, mantidas por ONGs ou fundações.

Por conta da covid-I9, existem vários estudos dentro e fora do país com foco em traçar novos caminhos para a sobrevivência da escola. Sabemos que há uma ex-

3 Empresa líder internacional de pesquisa de mercado baseada na internet, sediada no Reino Unido, com operações na Europa, América do Norte, Oriente Médio e Ásia-Pacífico.

4 "Desafiador" (em tradução livre). 
cepcionalidade no que vivemos agora, com distanciamento em todas as esferas da sociedade. No entanto, é evidente que o espaço de aprendizagem mudou em caráter definitivo. E terá de passar por desenvolvimento de habilidades cognitivas mais complexas, com as quais os alunos compartilhem, criem juntos e possam interagir na formação do seu próprio conhecimento.

No entanto, mesmo imersos nas tecnologias e sendo seus contemporâneos desde o nascimento, nem todos os alunos, hoje, têm fácil acesso a elas devido à pandemia.

O Centro Regional de Estudos para o Desenvolvimento da Sociedade da Informação (Cetic.br), um ano antes do isolamento social, fez um levantamento denominado "TIC Domicílios 20I9" e identificou que aproximadamente 30\% de todos os lares no Brasil não tinham acesso à internet.

E os problemas não se resumem a esse fato. As pesquisas evidenciaram que as adversidades apresentadas poderiam impactar em algum momento a educação no país. Como poucas providências foram tomadas pelos órgãos governamentais responsáveis nos últimos anos, a pandemia escancarou as inconveniências na educação do Brasil.

Como exemplo desses problemas podemos citar a exclusão digital por classe social. Os números das pesquisas informam que apenas I\% da classe A não tem conexão com a internet, enquanto metade das famílias com renda de no máximo I salário mínimo não tem acesso à rede em casa. E essa população sem acesso é predominantemente negra. E apenas $27,7 \%$ dos pretos ou pardos integram o conjunto dos IO\% com maiores rendimentos do país, mesmo representando $55,8 \%$ da população, como explicita o gráfico I (IBGE, 2020).

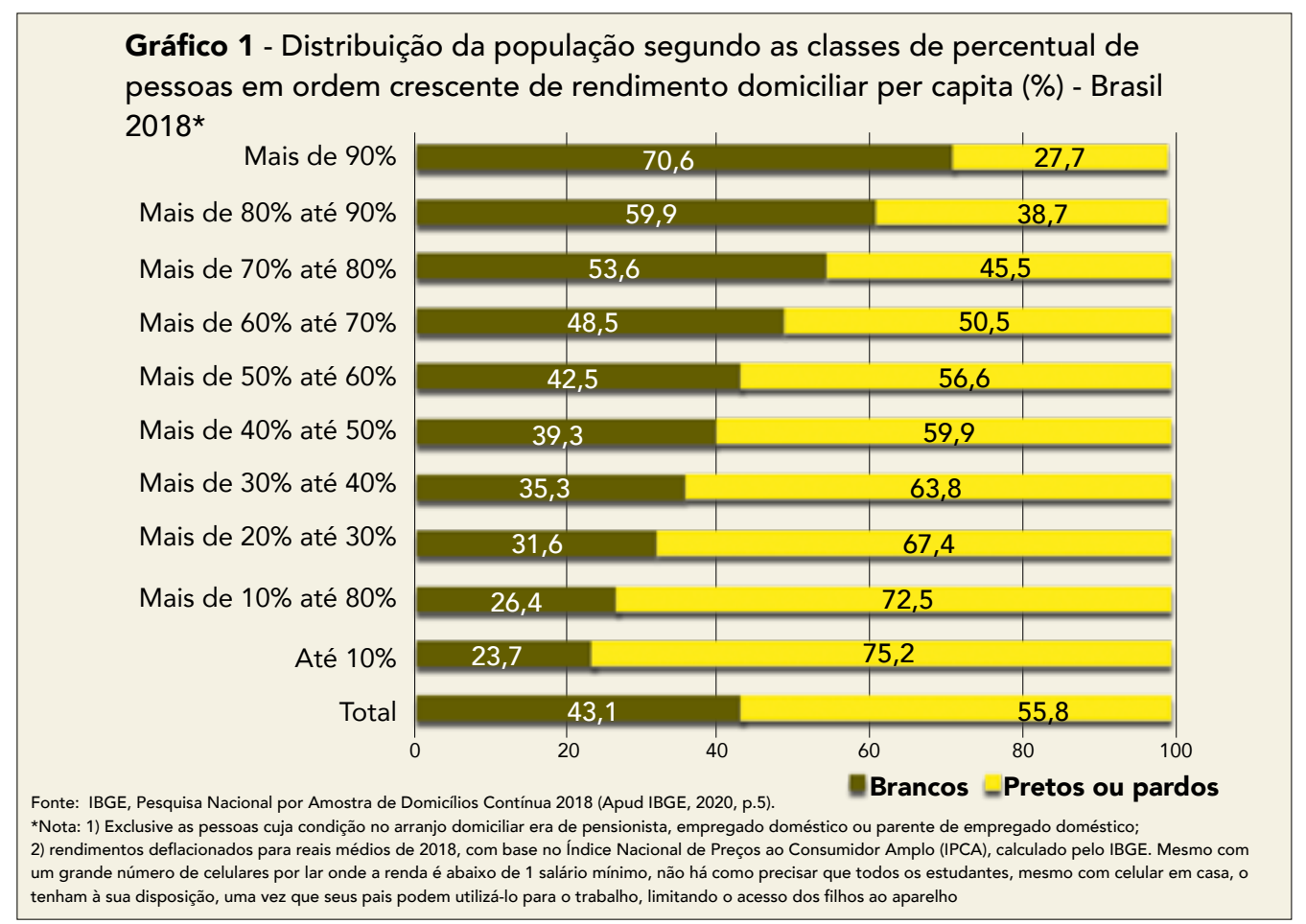


Foi também identificado nessa pesquisa que o aparelho eletrônico com maior presença nas residências brasileiras ainda é a TV (96\%). Mas o equipamento mais comum como meio de acesso à internet é o celular, que tem presença em $84 \%$ das camadas D e E, como mostra o gráfico 2 (IBGE, 2020).

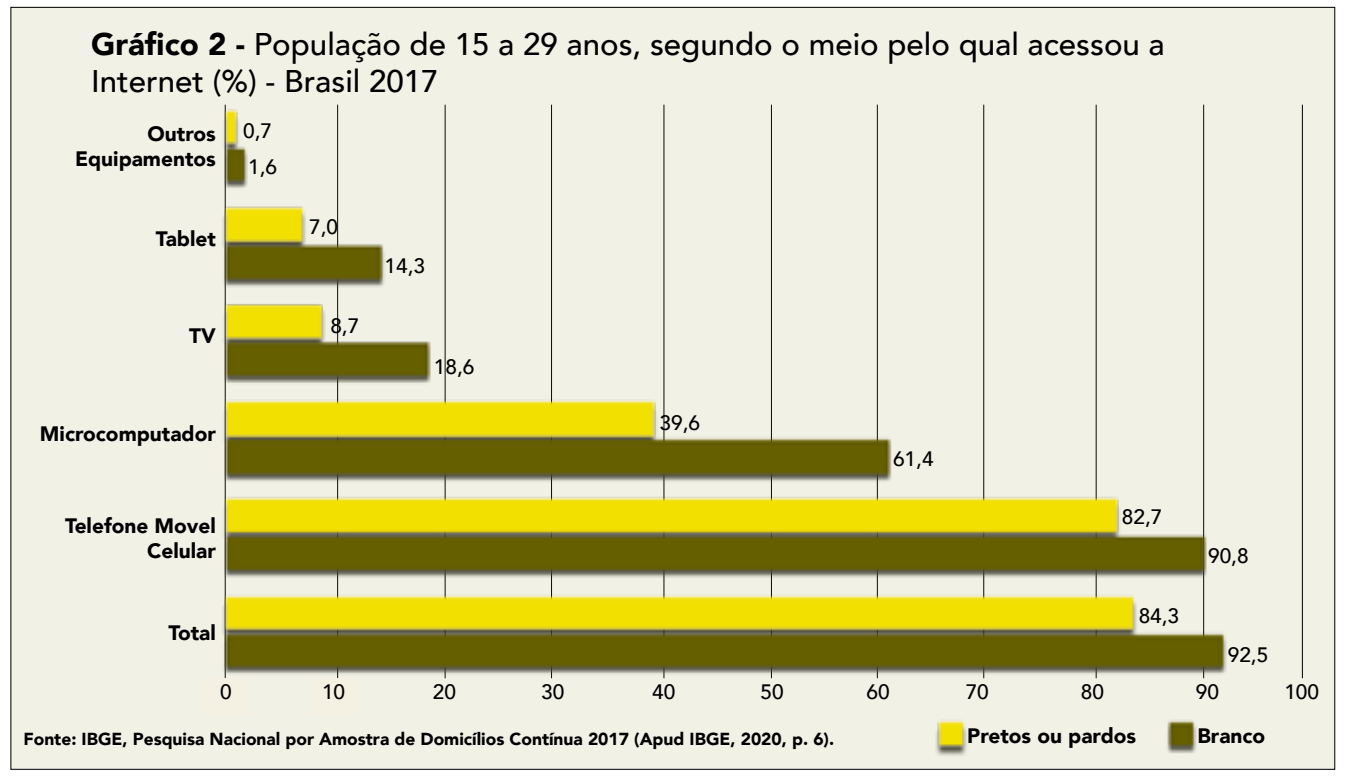

Ademais, os estudantes de baixa renda, além de não ter espaço para estudar em suas casas, não dispõem de equipamentos como computadores, tablets ou notebooks; a conexão com a internet, quando há, é sempre sofrível e com pacote limitado; suas pesquisas escolares constantemente se limitam ao acesso por celular, que não contempla todas as plataformas educacionais; além desses contratempos, as adaptações emergenciais feitas pelas escolas para as aulas remotas, sem estratégias ou conhecimentos prévios de ferramentas digitais educacionais, podem precarizar o ensino no país.

A maior porcentagem de brasileiros que nunca acessam a rede mundial de computadores está na zona rural do país. Nesta, 41\%, ou io milhões de brasileiros, conforme dados da Anatel e da Cetic.br, jamais usaram a internet.

Assim como, segundo o Fundo das Nações Unidas para a Infância (Unicef), na pesquisa "TIC Kids Online 20I9", o Brasil tem 4,8 milhões de crianças e adolescentes entre 9 e $\mathrm{I} 7$ anos sem acesso à internet em suas casas, o que corresponde a $17 \%$ da população brasileira dessa faixa etária.

Números de exclusão digital como os citados são problemas reais para a população. E vêm aquecendo o debate sobre a premência de que o acesso à internet seja listado entre os direitos humanos fundamentais, visto que são direitos da pessoa humana a informação, a cultura e a educação. E a internet, neste momento da história, cumpre papel fundamental para a disseminação desses direitos, como bem citado no preâmbulo da Declaração Universal dos Direitos do Homem, que afirma: 
A Assembleia Geral proclama a presente Declaração Universal dos Diretos Humanos como o ideal comum a ser atingido por todos os povos e todas as nações, com o objetivo de que cada indivíduo e cada órgão da sociedade, tendo sempre em mente esta declaração, se esforce, através do ensino e da educação, por promover o respeito a esses direitos e liberdades, e, pela adoção de medidas progressivas de caráter nacional e internacional, por assegurar o seu reconhecimento e a sua observância universal e efetiva, tanto entre os povos dos próprios Estados-Membros quanto entre os povos dos territórios sob sua jurisdição (ONU, I948).

Inspirada nessa declaração a Emenda Constitucional n. 85, de fevereiro de 2015, altera e adiciona dispositivos à Constituição Federal, responsabilizando juridicamente a União, Estados, Municípios e o Distrito Federal como agente de promoção e incentivo ao desenvolvimento científico, a pesquisa, a capacitação científica e tecnológica e a inovação.

Art. 23. É competência comum da União, dos Estados, do Distrito Federal e dos Municípios:

[...]

V - proporcionar os meios de acesso à cultura, à educação, à ciência, à tecnologia, à pesquisa e à inovação; (BRASIL, 20I5).

Dessa forma, a inclusão a rede mundial de computadores como direito humano fundamental cumpre tanto o requisito material como legal e constitucional de inclusão social.

\section{METODOLOGIA ATIVA E INOVATIVA}

Uma parte significativa dos professores são imigrantes digitais, que, antes do isolamento social, evitavam sair de suas zonas de conforto tecnológicos e experienciais, pagando um preço muito elevado por isso.

Para Prensky (200I), essa situação é muito séria, porque o maior problema que a educação enfrenta atualmente é que os nossos professores imigrantes digitais usam linguagens ultrapassadas, da era pré-digital, e, ainda, não conseguem explorar como precisam os recursos tecnológicos; portanto, estão batalhando para ensinar indivíduos que falam uma linguagem totalmente inédita.

E dessa nova linguagem resulta que os alunos sejam multitarefados, que prefiram a leitura de infográficos à dos textos, que escolham trabalhar de forma compartilhada, que prefiram hipertextos com acessos aleatórios, que optem por pequenas gratificações e recompensas constantes e sejam mais instigados por gamificação na aprendizagem. Por isso, o impacto das aulas remotas, com relação à capacidade de 
manuseio de ferramentas computacionais, foi menor para os alunos do que para os professores.

Essas características de imersão, que acompanham os estudantes desde o nascimento, são um importante princípio da active learning, ou aprendizagem ativa, em tradução literal. A escola precisa desenvolver metodologias ativas estratégicas que coloquem o estudante como o principal agente de seu aprendizado. Tendo o professor como estimulador das críticas e reflexões, mas o aluno como centro desse processo.

Salientando que, antes do isolamento social, as tecnologias usadas em sala de aula já estavam entrando em desuso ou desaparecerão em pouco tempo, segue-se uma exposição adaptada sobre prospecções feitas por Kelly (20I7) para os próximos anos em comparação as tecnologias utilizadas em 2020.

\begin{tabular}{|c|c|}
\hline \multicolumn{2}{|c|}{$\begin{array}{l}\text { Quadro } 2 \text { - Dez perspectivas da tecnologia educacional para a próxima } \\
\text { década. }\end{array}$} \\
\hline CAIRÃO EM DESUSO & SERÃO COMUNS \\
\hline Computadores, tablets e laptops; & Realidade aumentada/virtual e mista; \\
\hline $\begin{array}{l}\text { Telefones celulares digitais, telefones fixos e } \\
\text { analógicos; }\end{array}$ & Dispositivos móveis smarts e apps; \\
\hline Impressoras, escâneres e copiadoras; & Impressoras/escâneres/modelagem em 3D \\
\hline Projetores/retroprojetores; & Aprendizagem adaptativa e personalizada \\
\hline $\begin{array}{l}\text { Pendrives, HD's externos, CDs e DVDs e seus } \\
\text { aparelhos de reprodução; }\end{array}$ & Vídeo e transmissão \\
\hline Livros, cadernos, apostilas e folhas impressas; & $\begin{array}{l}\text { Ferramentas de colaboração e mídia social; } \\
\text { internet das coisas vestíveis }\end{array}$ \\
\hline $\begin{array}{l}\text { Sistemas de gerenciamento de aprendizagem } \\
\left(\text { LMS) }{ }^{\star} \text {; Apresentações tradicionais; }\right.\end{array}$ & $\begin{array}{l}\text { Próxima geração de sistemas de } \\
\text { gerenciamento de aprendizagem (LMSs*) }\end{array}$ \\
\hline Laboratórios de informática e Lan houses; & Áudio/videoconferência em tempo real \\
\hline Projetores não interativos; & $\begin{array}{l}\text { Ferramentas baseadas em nuvem; } \\
\text { hologramas, projetores e quadros brancos } \\
\text { interativos }\end{array}$ \\
\hline Quadros de giz/quadro branco & Internet livre, rápida e segura. \\
\hline
\end{tabular}

* LMS - Learning Management System

A prospecção de Kelly evidencia que será necessário democratizar, baratear e desenvolver competências e implementar tecnologias para impulsionar as práticas docentes em sala de aula.

Além das ferramentas supracitadas, as inteligências artificiais (IAs) na educação já vêm sendo testadas com aparente desenvoltura:

I. tutores inteligentes - sistemas de ensino personalizados, que identificam o nível de aprendizagem do aluno e qual seu sentimento em relação ao tema; Baseados em emoções, detectam falhas na aprendizagem e sugerem, de forma autônoma, estratégias possivelmente mais adequadas para cada situação; 
2. aprendizado com jogos - a gamificação levará para a sala de aula os conceitos lúdicos dos jogos. Com senso de progressão e melhoramento, que nos envolve ao jogarmos, esse método incentiva o aprendizado e a pontualidade e influencia o cérebro a sair da zona de conforto;

3. fim das barreiras idiomáticas - com a ferramenta de processamento de linguagem natural (PLN), o sistema computacional interpreta e entende a linguagem humana, inclusive gírias. Usando fones tradutores e microfone, um japonês poderá dar aula de informática no Brasil em tempo real e sem falar português;

4. robótica como parâmetro curricular — a robótica já invade as escolas, desafiando, inovando e fortalecendo o raciocínio lógico. A competição mediante resolução de problemas da vida real com missões específicas já está sendo pensada;

5. criatividade computacional - terá a função de avaliar atividades criativas dos estudantes, gerando exemplos de exercícios inovadores de forma automática e potencializando os conteúdos educacionais on-line;

6. análise de aprendizagem (learning analytics) — será possível identificar os pontos complexos para a compreensão dos conteúdos ou a propensão a desistir de determinada disciplina com base nos dados coletados de todos os alunos.

Essas metodologias ativas adicionadas às TDICs podem facilitar o processo de ensino-aprendizagem e passaram a ser conhecidas na literatura como aprendizagem tecnológica ativa (ATA) por terem como base a autonomia do aluno, sendo o docente o intermediador do conhecimento. Mas, para que assim sejam denominadas, precisarão estar alicerçadas em um processo de aprendizagem ativo composto por cinco pilares: o papel do docente; o protagonismo do aluno; o suporte das tecnologias; a aprendizagem; e a avaliação.

É importante salientar que o papel do docente é primordial para a execução, orientação, supervisão e facilitação de todo o processo de aprendizagem do aluno; no entanto, o professor não será a única fonte de informação e conhecimento.

Precisamos identificar quais tecnologias podem gerar ações que motivem a prática docente. Mesmo que elas não sejam muito atrativas para os imigrantes digitais, é necessário expurgar essa espécie de tecnofobia para evitar um maior abismo social. Em razão disso, é impreterível mapear e formar competências por meio de políticas públicas voltadas para a escola pública.

O próprio PNE 2014-2024, instituído pela lei no $13.005 / 2014$, versa sobre a necessidade de planejar, orientar e desenvolver políticas públicas na educação ao longo dos anos daquele decênio.

Podemos dizer, resumidamente, que as estratégias traçadas pelo PNE para as tecnologias na educação concentram-se em: 
- desenvolver, selecionar, difundir e incorporar tecnologias pedagógicas e educacionais no dia a dia escolar;

- incentivar a formação continuada docente e a participação dos estudantes em cursos científico-tecnológicos;

- informatizar as escolas e universalizar o acesso à rede mundial de computadores.

A tramitação dessa lei federal de 2014 e sua relação com os debates em torno da necessidade da implementação da tecnologia na escola podem ser definidas como um avanço significativo, assim como as mobilizações sociais, oriundas das novas exigências do mercado, e seus reflexos no Congresso Nacional.

No entanto, é necessário reforçar que as tecnologias não se contrapõem nem pretendem substituir o professor e seus métodos. A integração dele no processo de ensino e aprendizagem só deverá gerar bons resultados quando o docente, por meio de políticas públicas sérias, desenvolver competências múltiplas para acessar as mais variadas mídias e interagir com elas. Ou seja, precisará estar letrado digitalmente.

Para Yarzábal (2002), por exemplo, a sociedade do conhecimento não está obrigatoriamente condicionada às TDICs, no entanto estas permitem e facilitam os cenários de conhecimento, o compartilhamento de diferentes informações das mais diversas partes do mundo e, com isso, alavancam o processo de criação e de disseminação do conhecimento.

\section{LETRAMENTO DIGITAL}

Na contemporaneidade, os principais ativos são a informação e o conhecimento. E não se trata apenas de compilação de dados. É elementar entendermos que conhecimento não é mais monodisciplinar, mas sim interdisciplinar, está centrado no problema, não na disciplina. É produzido em diversos âmbitos mais próximos da sua aplicação, deslocou-se dos círculos acadêmicos para aproximar-se dos círculos produtivos empresariais e industriais. Utiliza intensamente redes eletrônicas para fins de intercâmbio, produção e transformação em tecnologia e está sujeito a controles de qualidade diversificados, de forma que o simples controle pela avaliação pelos pares tornou-se obsoleto. Agora precisa demonstrar sua relevância social e eficiência econômica, e tem que mostrar sua qualidade de outras formas que ultrapassem a avaliação por seus pares (YARZÁBAL, 2002, p. I2).

É necessário considerar que a geração da era do conhecimento tem uma constituição de raciocínio que difere daquela da geração $\mathrm{X}$, e por isso requer competências, habilidades e atitudes distintas.

É preciso ensinar no mundo, e não mais sobre o mundo. É fundamental fazer parte do problema, em vez de simular o problema em ambientes controla- 
dos. É essencial entender que a escola não é um mundo à parte, que a sala de aula não é um lugar específico, mas um grupo de pessoas, que os problemas do mundo moldam a sala de aula e que pessoas e suas histórias e contextos são parte desse problema. Esse é um retrato do que é a educação no século XXI. Esse tipo de transversalidade pode, a princípio, gerar insegurança e receio iniciais, e até mesmo um questionamento sobre o ponto de partida (MARTINS FILHO; GERGES; FIALHO, 20I5, p. 582).

Posto isso, é levantada a hipótese de que há necessidade de "alfabytezar" os professores, ou seja, garantir o letramento digital para que os docentes possam desenvolver competências em tecnologias da informação e, assim, desenvolver habilidades para ensinar uma geração de nativos digitais.

O letramento digital não é, de modo algum, congênere do letramento analógico, uma vez que o analógico se limita no tempo, tamanho e espaço, e o digital pode ser expandido em uma cauda longa de conhecimento exponencial. Consequentemente, o letramento digital precisa ser aprofundado e utilizado nas disciplinas com o intuito de discutir problemas de alta complexidade em situações reais.

Para essa finalidade, os docentes precisam ter acesso a dispositivos digitais, como os móveis, para o desenvolvimento de didáticas pedagógicas mais coesas. Pois, como bem explanam Lemos (2005, p.I5) e Santaella (2013, p. 304), respectivamente,

a internet fixa mostrou o potencial agregador das tecnologias de comunicação. Agora a internet móvel está aproximando o homem do desejo de ubiquidade fazendo emergir uma nova cultura telemática, com novas formas de consumo de informação e com novas práticas de sociabilidade.

E

é justamente isso que tem ocorrido com os dispositivos móveis, cuja velocidade de absorção e domesticação vem se dando em progressão geométrica espantosa.

Porém, para que estes não se tornem banais ferramentas de reprodução de conteúdo, o docente precisará ater-se à percepção de que não é a ferramenta que aprofundará o conhecimento, visto que ela é só uma ferramenta, e dependerá do significado que o professor atribuir à aprendizagem, para a concepção de novos conhecimentos.

\section{TECNOLOGIAS COMPUTACIONAIS NA SALA DE AULA EM TEMPO DE PANDEMIA}

As novas condições impostas para a docência em todos os níveis educacionais, em tempos de covid-I9, exigem dos professores um exercício de autoletramento, como está exposto na pesquisa realizada pela Fundação Carlos Chagas (FCC) em 2020, com I4.285 docentes em 27 unidades da Federação. Esse estudo mostrou que a 
rotina de trabalho pós-isolamento social preocupa os docentes quanto à reorganização das suas aulas, o seu tempo com os alunos e a tentativa de garantir sua autoformação tecnológica. O gráfico 3 demonstra as estratégias utilizadas pelos docentes:

Gráfico 3 - Aumento das atividades docentes (\%) - 2020

Dar apoio ou suporte a/relacionar-se com as famílias dos alunos

Participar de reuniões pedagógicas a distância

Assistir a/participação de cursos a distância

Ministrar aulas com novos recursos/ferramentas

Planejar/preparar aulas com novos recursos/ferramentas

Escrever/reponder a e-mail/WhatsApp/SMS

68,3

73,2

77,4

79,8

80,1

91,4

Fonte: FCC (2020)

Entre as estratégias educacionais utilizadas no intuito de garantir os conteúdos das disciplinas e otimizar o tempo, podemos destacar o estreitamento da comunicação com as famílias para estimular e acompanhar as atividades realizadas em casa, como mostra o gráfico 4 , a seguir:

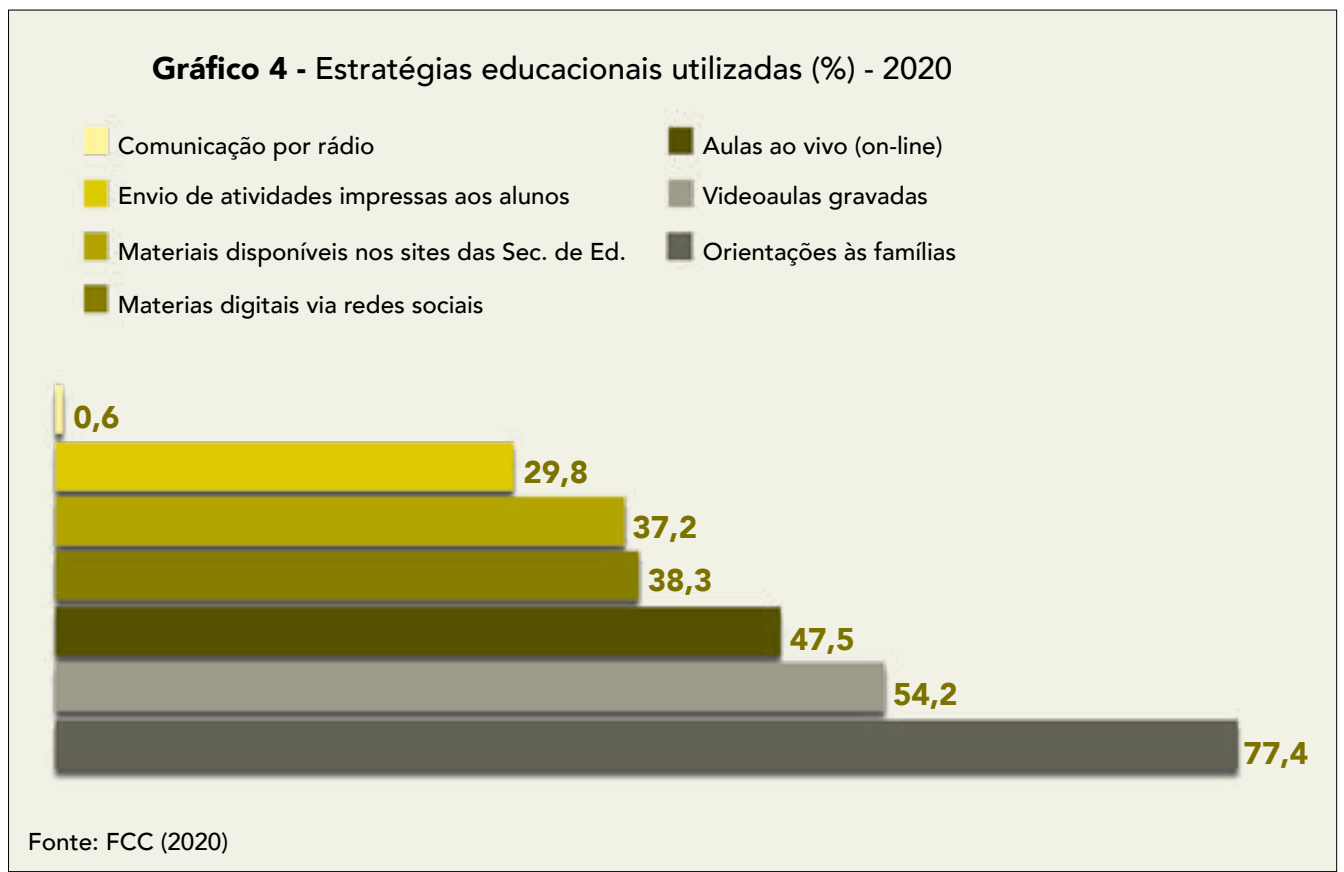




\section{Nesse período alunos e professores vêm}

se adaptando e aprendendo juntos com

novos programas, aplicativos e ferramentas

diversas. Os recursos educacionais

disponíveis aos professores variam

significativamente em complexidade

e recursividade. Em muitos casos, sua

utilização não pode ser responsabilidade

apenas do professor, pois somente pode

ser acessada em ambientes computacionais

relativamente grandes

Embora a pesquisa também tenha indicado que quase 8 em cada Io professores façam uso contínuo de materiais digitais por meio de redes sociais de forma estratégica, eles não se limitam a essa ferramenta, e reinventam seus métodos gravando aulas, se comunicando por rádio e desenvolvendo materiais impressos, entre outras novidades.

E nesse período alunos e professores vêm se adaptando e aprendendo juntos com novos programas, aplicativos e ferramentas diversas. Os recursos educacionais disponíveis aos professores variam significativamente em complexidade e recursividade. Em muitos casos, sua utilização não pode ser responsabilidade apenas do professor, pois somente pode ser acessada em ambientes computacionais relativamente grandes. No quadro a seguir, apontamos um conjunto de ferramentas que podem ser utilizadas de muitas formas, e que se tornaram comuns para grande número de usuários, considerando alunos e professores.

Quadro 3 - Programas e aplicativos mais usados em aulas remotas 2020

\begin{tabular}{|l|l|}
\hline Programa/aplicativo & O que é e para que serve? \\
\hline YouTube & $\begin{array}{l}\text { É uma plataforma de compartilhamento de vídeos. Pode ser } \\
\text { usado como repositório de aulas gravadas e transmissão de lives } \\
\text { educacionais, e possibilita a reprodução de vídeos, documentá- } \\
\text { rios, músicas, filmes e podcasts. }\end{array}$ \\
\hline Google Classroom & $\begin{array}{l}\text { É um sistema de gerenciamento de conteúdo gratuito para } \\
\text { escolas, organizações sem fins lucrativos e usuários com conta } \\
\text { pessoal. Por meio dessa plataforma, o professor pode enviar } \\
\text { mensagens aos alunos e organizar aulas a distância, ou, ainda, } \\
\text { enviar atividades síncronas e assíncronas. }\end{array}$ \\
\hline
\end{tabular}




\begin{tabular}{|c|c|}
\hline Google Docs & $\begin{array}{l}\text { Composto por quatro partes — documentos, apresentação, } \\
\text { planilha e desenho - é um aplicativo que pode ser utilizado de } \\
\text { forma síncrona e assíncrona. Por meio dele os usuários podem } \\
\text { escrever, editar e colaborar onde estiverem e ao mesmo tempo. } \\
\text { Esse aplicativo, embora pago, tem uma parte gratuita com aces- } \\
\text { so por login e senha. }\end{array}$ \\
\hline Google Drive & $\begin{array}{l}\text { É um serviço de armazenamento seguro na nuvem da Google } \\
\text { para conteúdo pessoal. Nele, cada usuário dispõe de } 15 \mathrm{~GB} \text { gra- } \\
\text { tuitos de espaço para enviar fotos, vídeos, documentos e outros } \\
\text { arquivos importantes; pode ser acessado em qualquer equipa- } \\
\text { mento, com login e senha individual. }\end{array}$ \\
\hline Google Meet & $\begin{array}{l}\text { É um serviço de comunicação por vídeo desenvolvido pela } \\
\text { Google que, embora seja paga, tem versão de acesso grátis. É } \\
\text { utilizado para videoconferências, chats e pode ainda gravar reu- } \\
\text { niões. Na versão gratuita, comporta até cem pessoas. Atualmen- } \\
\text { te, no Brasil, é o aplicativo mais usado para esse fim. }\end{array}$ \\
\hline Moodle & $\begin{array}{l}\text { É um sistema de software livre para a criação de cursos on-line } \\
\text { (EaD). A plataforma funciona como ferramenta de apoio para } \\
\text { alunos e professores. No Brasil, o Moodle é mais utilizado em } \\
\text { universidades, inclusive corporativas, e em cursos de idiomas, } \\
\text { uma vez que é o formato mais próximo da modalidade de aula } \\
\text { presencial. }\end{array}$ \\
\hline Redes sociais & $\begin{array}{l}\text { Fornecendo inúmeras funcionalidades e diversos aplicativos, } \\
\text { as redes sociais possibilitam e facilitam o compartilhamento de } \\
\text { ideias e informações e podem enriquecer o processo de ensi- } \\
\text { no-aprendizagem. As mais utilizadas são Facebook, WhatsApp, } \\
\text { Twitter e Instagram. }\end{array}$ \\
\hline Jitsi Meet & $\begin{array}{l}\text { É uma aplicação de software livre, multiplataforma, para voz e } \\
\text { videoconferência, que permite fazer chamadas gratuitas com até } \\
20 \text { pessoas e compartilhamento de tela, gravação de reuniões, } \\
\text { transmissão e chamadas ao vivo em seu canal, dispensando o } \\
\text { login. Não é necessário baixar o aplicativo. Todas as reuniões } \\
\text { são criptografadas, tornando-a a plataforma mais segura para a } \\
\text { realização de chamadas importantes na internet. }\end{array}$ \\
\hline OBS Studio & $\begin{array}{l}\text { É um software gratuito usado para gravar vídeos, gravar a tela } \\
\text { do computador ou fazer transmissão ao vivo de aulas no YouTu- } \\
\text { be ou redes sociais. Tem sido usado com frequência para gravar } \\
\text { aulas, mas é preciso notar que esse aplicativo não possui edição } \\
\text { de vídeos. }\end{array}$ \\
\hline Shotcut & $\begin{array}{l}\text { É um aplicativo gratuito para edição de vídeos que suporta dife- } \\
\text { rentes formatos de imagens e vídeos. Conta com interface ami- } \\
\text { gável e em português. Com diversos recursos, esse app permite } \\
\text { personalizar filtros de áudio e vídeo. }\end{array}$ \\
\hline StreamYard & $\begin{array}{l}\text { É um estúdio virtual que permite reunir até dez pessoas para } \\
\text { lives, sendo controlado pelo navegador; transmite vídeos direta- } \\
\text { mente nas principais redes sociais, e por conta disso é bastante } \\
\text { usado em entrevistas, rodas de discussões e eventos on-line. } \\
\text { Traz uma identidade profissional à transmissão. Na versão gratui- } \\
\text { ta, é restrito a no máximo } 20 \text { h de transmissão por mês, obriga- } \\
\text { toriedade de marca d'água do app e limite de seis convidados } \\
\text { por tela. }\end{array}$ \\
\hline
\end{tabular}




\begin{tabular}{|l|l|}
\hline \multirow{2}{*}{ Zoom } & $\begin{array}{l}\text { É uma ferramenta de videoconferência que, na versão gratuita } \\
\text { para usuários individuais, comporta até } 25 \text { pessoas. É a solução } \\
\text { mais usada do mundo nesse segmento. A estabilidade de cone- } \\
\text { xão em qualquer dispositivo é sua principal vantagem. O progra- } \\
\text { ma permite ainda que o usuário participe por ligação telefônica } \\
\text { convencional; o convite de participação pode ser por e-mail, } \\
\text { redes sociais e SMS, entre outros. }\end{array}$ \\
\hline Gimp & $\begin{array}{l}\text { O GNU (GNU Image Manipulation Program), conhecido por } \\
\text { Melhor alternativa ao caríssimo Photoshop, o aplicativo reúne } \\
\text { uma série de recursos utilizados na criação ou manipulação de } \\
\text { imagens e fotografias e na criação de gráficos e logotipos; altera } \\
\text { cores, remove partes indesejadas e suporta, salva, exibe e possi- } \\
\text { bilita diversos formatos de imagem, inclusive PDF. }\end{array}$ \\
\hline
\end{tabular}

Fonte: elaboração das autoras Lopes e Melo

* Todas as ferramentas apresentadas têm versão grátis ou códigos de desenvolvimento totalmente livres e gratuitos.

Esses aplicativos e programas citados nesse estudo foram testados pelas autoras Lopes e Melo de forma planejada e sistemática, e são exemplos de ferramentas que podem auxiliar o professor em suas aulas, tanto na modalidade presencial quanto na mista ou remota, desde que planejadas. E assim como esses, há inúmeros aplicativos, jogos, programas à disposição na internet e nas lojas de aplicativos na versão paga ou gratuita, que podem ser explorados e compartilhados pelos docentes como boas práticas e permitem futuros estudos para ajudar os docentes na associação entre tecnologias e suas práticas pedagógicas.

\section{POTENCIAL DOS DISPOSITIVOS MÓVEIS NA EDUCAÇ̃̃O}

Cotidianamente, a presença de dispositivos tecnológicos em sala de aula causava, quase sempre, motivo de desconforto aos docentes e familiares, como bem acentuam Grund e Gil (20II).

Durante o caminho percorrido para a integração dos dispositivos móveis em sala de aula, é encontrada resistência das famílias e dos professores, pois eles consideram esses dispositivos mais como meios de comunicação e entretenimento do que como possíveis ferramentas educativas (apud CLEOPHAS et al, 20I3, p.3).

Antes da pandemia, estudos acadêmicos já mostravam que as duas últimas gerações, e as que virão, serão protagonistas de um desafio bem diferente e que pode se chocar com a promoção do ensino, se o professor não estiver adequado aos novos tempos. O isolamento social acelerou esse quadro. O "novo normal” e sua geração não se adequarão a uma educação descontextualizada dos seus interesses, que ignore seus anseios digitais e os benefícios das múltiplas tecnologias. 


\section{As problemáticas discutidas neste estudo apontam, ainda, a necessidade de repensar as políticas públicas voltadas para a educação de modo sistematizado, planejado e em caráter de urgência, para que elas contem com infraestrutura adequada e a criação de escolas virtuais públicas, apoiadas pelo Estado}

Os principais mediadores desses recursos vêm da geração $\mathrm{Z}$, nascida após 1992, e da geração Alpha, nascida após 20I0, submersas num natural e progressivo contexto tecnológico desde o nascimento.

Para Leite (20I5), os nativos digitais tendem a lidar com as novas tecnologias de forma natural, como se elas fossem a sua língua materna, adaptando-se ao novo sem receio das inconstâncias e das rápidas evoluções tecnológicas.

Entre esses artefatos tecnológicos, os dispositivos móveis - dentro desta categoria se enquadram os smartphones, tablets, netbooks, games, laptops, media players (iPods e similares), ultrabooks e consoles - apresentam os mesmos conceitos de ubiquidade e mobilidade.

Hayles (2005) diz que a constituição de nossa subjetividade está intimamente vinculada às tecnologias que nos rodeiam. E em nossa sociedade da informação e comunicação, os aparelhos de telefonia inteligentes, smarts, garantem ao usuário a onipresença das TDICs comunicacional e informacional e, simultaneamente, a mobilidade, o que os torna instrumentos praticamente indispensáveis para uma grande parcela da população, e que podem ser usados a favor da educação. A utilização de tecnologias como e-learning, m-learning, realidade aumentada/virtual, entre outras, deve ser explorada nos próximos anos com maior frequência, pois a tecnologia está convergindo para a mobilidade e portabilidade.

\section{CONSIDERAÇ̃̃ES FINAIS}

Há alguns anos, as tecnologias vêm interferindo no nosso cotidiano em velocidade exponencial, causando mudanças e impactos positivos e negativos na sociedade. Como vastamente ventilado neste estudo, essas transformações se acentuaram no ano de 2020 por conta de uma crise sanitária que abateu o país, a pandemia de covid-I9. Escolas fecharam e as aulas presenciais foram substituídas, por força da lei 
e em caráter excepcional, por aulas remotas que utilizam meios e tecnologias de informação e comunicação para atender a portarias do Ministério da Saúde que versam sobre a obrigatoriedade de isolamento social.

Esse contexto evidenciou o que vários estudos e pesquisas científicas já apontavam: não temos infraestrutura adequada, há dificuldade dos professores em seguir um programa pontual e pessoal de educação continuada, a escola sofre com a carência de atuação governamental que possa viabilizar um conjunto de ações para a educação.

As problemáticas discutidas neste estudo apontam, ainda, a necessidade de repensar as políticas públicas voltadas para a educação de modo sistematizado, planejado e em caráter de urgência, para que elas contem com infraestrutura adequada e a criação de escolas virtuais públicas, apoiadas pelo Estado.

É preciso rever a grade curricular das licenciaturas e de outros cursos que se dediquem à formação de professores, no sentido de promover, na medida do possível, a experimentação de tecnologias, tanto para a própria dinâmica deles como para suas práticas pedagógicas, inclusive no que diz respeito à habilidade para enfrentamento de situações atípicas como a que estamos vivendo.

Também é necessário perceber os aspectos mais evidentes das novas tecnologias da informação: as metodologias inclusivas, pedagogias ativas, compartilhamento de informações e cooperação de ideias, para que possamos ter fôlego ao desenvolver criticidade nos alunos e, na medida do possível, garantir a equidade na escola.

Assim, a escola não pode ficar alheia às inovações tecnológicas, dado que, para o alcance de um patamar satisfatório, boa vontade e desejo não são suficientes. São imprescindíveis programas e projetos de valor educacional voltados para tecnologias como cerne da política. O distanciamento das tecnologias da informação é um dos mais graves equívocos para a estrutura escolar, como percebe Ferreira (1997, p. 87), ao preconizar que a escola, local onde se deveria produzir conhecimento, não fique à margem da maior fonte de informação disponível neste momento.

* Mestranda em Educação Profissional pela Universidade de Pernambuco (UPE). Analista em Desenho Instrucional do Serviço Federal de Processamento de Dados (Serpro).

** Doutora em Educação. Professora pesquisadora do Programa de Mestrado Profissional em Educação e de Licenciatura em História da UPE.

Texto recebido em outubro de 2020; aprovado em novembro de 2020. 
AKELLA, Devi. Learning together: Kolb's experiential theory and its application. Journal of Management and Organization, v. 16, n. 1, p. 100-112, mar. 2010. Disponivel em: <https://www.researchgate.net/publication/247920250_Learning_together_Kolb's_experiential_theory_and_its_application>. Acesso em: 18 nov. 2020.

ALLESSANDRINI, Cristina Dias. O desenvolvimento de competências e a participação pessoal na construção de um novo modelo educacional. In: PERRENOUD, Philippe et al. As competências para ensinar no século XXI: a formação dos professores e o desafio da avaliação. Porto Alegre: Artmed, 2002. p. 157-76.

BANCO MUNDIAL. covid-19 no Brasil: impactos e respostas de políticas públicas. Banco Mundial, jun. 2020. Disponível em: <http://documents1.worldbank.org/curated/en/106541594362022984/ pdf/COVID-19-in-Brazil-Impacts-and-Policy-Responses.pdf>. Acesso em: 18 set. 2020.

BRASIL. Emenda Constitucional $\mathbf{N}^{\circ} 85$ de 26 de fevereiro de 2015. Altera e adiciona dispositivos na Constituição Federal para atualizar o tratamento das atividades de ciência, tecnologia e inovação. Diário Oficial da União, Brasília, DF, 27 fev. 2015. Disponível em: <http://www.planalto.gov.br/ccivil_03/Constituicao/Emendas/Emc/emc85.htm.> Acesso em: Acesso em: 17 nov. 2020.

Ministério da Educação. Base Nacional Comum Curricular. Brasília: MEC, 2017. Disponível em: <http://basenacionalcomum.mec.gov.br/images/BNCC_El_EF_110518_versaofinal_site.pdf>. Acesso em: 18 nov. 2020.

Ministério da Educação. Lei de Diretrizes e Bases da Educação Nacional. Lei n 9 9.394/1996. Brasília: MEC, 20 dez. 1996. Disponível em: <www.planalto.gov.br/ccivil_03/Leis/L9394.htm>. Acesso em: 18 set. 2020.

Ministério da Educação. Plano de Nacional de Educação. Lei n 13.005/2014. Brasília: MEC, 2014. Disponível em: <http://pne.mec.gov.br/18-planos-subnacionais-de-educacao/543-plano-nacional-de-educacao-lei-n-13-005-2014>. Acesso em: 23 set. 2020.

Ministério da Educação. Portaria n 343, de 17 de março de 2020. Brasília: MEC, 2020. Disponível em: <www.in.gov.br/en/web/dou/-/portaria-n-343-de-17-de-marco-de-2020-248564376>. Acesso em: 6 nov. 2020.

CASTELLS, Manuel. A sociedade em rede. São Paulo: Paz e Terra, 1999.

CETIC.BR. TIC Domicílios 2019: apresentação dos principais resultados para a imprensa. 2019. Disponível em: <https://cetic.br/pt/pesquisa/domicilios/analises>. Acesso em: 23 set. 2020.

DIAS, Érika; PINTO, Fátima Cunha Ferreira. A educação e a covid-19. Ensaio: Avaliação e Políticas Públicas em Educação, Rio de Janeiro, v. 28, n. 108, p. 545-554, jul.-set. 2020. Disponível em: <https://doi.org/10.1590/s0104-40362019002801080001>. Acesso em: 27 ago. 2020.

ELKJAER, Bente. Em busca de uma teoria de aprendizagem social. In: EASTERBY-SMITH, Mark; BURGOYNE, John; ARAÚJO, Luis (Org.). Aprendizagem organizacional e organização de aprendizagem. São Paulo: Atlas, 2000. p. 100-116.

FCC. Pesquisa: educação escolar em tempos de pandemia na visão de professoras/es da educação básica. Fundação Carlos Chagas, 2020. Disponível em: <www.fcc.org.br/fcc/educacao-pesquisa/educacao-escolar-em-tempos-de-pandemia-informe-n-1>. Acesso em: 30 set. 2020.

FERREIRA, Carlos Augusto Lima. O ensino de história nas escolas de ensino fundamental e médio de Salvador de Bahia: análises de variáveis e a contribuição do computador. 1997. Dissertação (Mestrado em Pedagogia Aplicada) — Universitat Autónoma de Barcelona, Barcelona, 1997.

FRAGA, Renê. Pesquisa do Google revela que 95\% dos professores brasileiros acreditam que a tecnologia é benéfica aos estudantes. Google Discovery, 17 ago. 2019. Disponível em: <https://googlediscovery.com/2019/08/17/pesquisa-do-google-revela-que-95-dos-professores-brasileiros-acreditam-que-a-tecnologia-e-benefica-aos-estudantes>. Acesso em: 23 set. 2020. 
FREIRE, Paulo. Educação e mudança. 30. ed. Rio de Janeiro: Paz e Terra, 2007.

Pedagogia da autonomia: saberes necessários à prática educativa. 35 ed. São Paulo: Paz e Terra, 2007. (Coleção Leitura.)

GRUND, F.B ; GIL, D.J.G, 2011 Apud CLEOPHAS, M.G.P; LINS, W.C.B; LEÃO, M.B.C. Usabilidade dos dispositivos móveis: verificando a confiabilidade de um questionário a partir da aplicação do coeficiente alfa de Cronbach. Atas do IX Encontro Nacional de Pesquisa em Educação em Ciências. Águas de Lindóia, São Paulo. p.3. 2013.HAYLES, Katherine N. My mother was a computer: digital subjects and literary text. Chicago: The University of Chicago Press, 2005. Disponível em: <http:// www.eneq2016.ufsc.br/anais/resumos/R1292-2.pdf> Acesso em: 18 nov. 2020.

IBGE. Desigualdades sociais por cor ou raça no Brasil. Rio de Janeiro: IBGE, 2020. Disponível em: <https://biblioteca.ibge.gov.br/visualizacao/livros/liv101681_informativo.pdf>.Acesso em: 30 set. 2020.

IMBERNÓN, Francisco. Formação docente e profissional. São Paulo: Cortez, 2000.

JONASSEN, David H. Computer as mindtools for schools: engaging critical thinking. Columbus: Pennsylvania State University, 2000.

KELLY, Rhea. Teaching with technology survey. Campus Technology, v. 30, n. 7, 2017.

KOLB, David. Experiential learning. New Jersey: Prentice Hall, 1984.

LEITE, Bruno S. Tecnologias no ensino de Química: teoria e prática no ensino de Química. 1. ed. Curitiba: Appris, 2015.

LEMOS, André. Cibercultura e mobilidade: a era da conexão. In: CONGRESSO BRASILEIRO DE CIÊNCIAS DA COMUNICAÇÃO, 28., 5-9 set. 2005, Rio de Janeiro. Anais eletrônicos... Rio de Janeiro: Uerj, 2005. Disponível em: <www.intercom.org.br/papers/nacionais/2005/resumos/R1465-1.pdf>. Acesso em: 18 fev. 2020.

MARTINS FILHO, Vilson; GERGES, Nina Rosa Cruz; FIALHO, Francisco Antonio Pereira. Design thinking, cognição e educação no século XXI. Revista Diálogo Educacional, v. 15, n. 45, p. 582, maio-ago. 2015..

MOODLE. Guia rápido do professor. Disponível em: < https://docs.moodle.org/all/pt_br/Guia_r\%C3\%A1pido_do_professor >. Acesso em: 18 nov. 2020.

MORÁN, José Manuel. Mudando a educação com metodologias ativas. In: SOUZA, Carlos Alberto de; MORALES, Ofelia Elisa Torres (Org.). Convergências midiáticas, educação e cidadania: aproximações jovens. Ponta Grossa: Proex-UEPG, 2015. v. 2. p. 15-31 Disponível em <www2.eca.usp.br/moran/ wp-ontent/uploads/2013/12/mudando_moran.pdf>. Acesso em: 27 fev. 2020.

MOURA, Adelina. Práticas de mobile learning no ensino básico e secundário: metodologias e desafios. In: ENCONTRO SOBRE JOGOS E MOBILE LEARNING, 3., 2016, Coimbra. Anais... Coimbra, 2016. p. 19.

ONU. Declaração Universal dos Direitos Humanos. Paris: ONU, 1948. Disponível em : < https:// www.ohchr.org/EN/UDHR/Documents/UDHR_Translations/por.pdf >. Acesso em: 18 nov. 2020.

PAPERT, Seymour. Logo: computadores e educação. São Paulo: Brasiliense, 1985.

The children's machine: rethinking school in the age of the computer. New York: Basic Books, 1993.

PIMENTEL, Alessandra. A teoria da aprendizagem experiencial como alicerce de estudos sobre desenvolvimento profissional. Estudos de Psicologia, v. 2, n. 2, p. 159-168, 2007. Disponível em: <www. scielo.br/pdf/epsic/v12n2/a08v12n2.pdf>. Acesso em: 18 set. 2020.

PRENSKY, Marc. Nativos digitais, imigrantes digitais. Tradução Roberta de Moraes Jesus de Souza. On the Horizon, v. 9, n. 5, out. 2001. Disponível em: <http://poetadasmoreninhas.pbworks.com/w/ file/fetch/60222961/Prensky\%20-\%20Imigrantes\%20e\%20nativos\%20digitais.pdf>. Acesso em: 23 jan. 2020. 
Digital natives, digital immigrants. On the Horizon, v. 9, n. 5, out. 2001. Disponível em: $<$ www.marcprensky.com/writing/Prensky\%20-\%20Digital\%20Natives,\%20Digital\%2Olmmigrants\%20 -\%20Part1.pdf>. Acesso em 15 jul. 2020.

RESNICK, Mitchel; OCKO, Stephen; PAPERT, Seymour. Lego/logo: learning through and about design. In: HAREL, Idit; PAPERT, Seymour (Ed.). Constructionism. Norwood: Ablex, 1991.

SANTAELLA, Lucia. Comunicação ubíqua: repercussões na cultura e na educação. São Paulo: Paulus, 2013. (Coleção Comunicação.)

THE WORLD BANK. The economy in the time of covid-19. The World Bank, abr. 2020. Disponível em: <www.abdib.org.br/wp-content/uploads/2020/04/Banco-Mundial_-Coronav\%C3\%ADrus.pdf>. Acesso em: 18 set. 2020.

UNESCO. TIC na educação do Brasil. Brasília, s.d. Disponível em: <https://pt.unesco.org/fieldoffice/ brasilia/expertise/ict-education-brazil>. Acesso em: 26 jun. 2020.

VALENTE, José Armando; ALMEIDA, Fernando José de. Visão analítica da informática na educação no Brasil: a questão da formação do professor. Revista Brasileira de Informática na Educação, n. 1, 1997.

VINCENT-LANCRIN, Stéphan et al. Measuring innovation in education 2019: what has changed in the classroom?. Paris: OECD, 5 mar. 2019. Disponível em: <https://doi.org/10.1787/9789264311671en>. Acesso em: 26 jun. 2020.

YARZÁBAL, Luis. Consenso para el cambio en la educación superior. Caracas: Unesco; lesalc, 2002. 